\title{
Missed Gastric Injuries in Blunt Abdominal Trauma Case report with review of literature
}

*Ahmed A. Naiem, ${ }^{1}$ Kadhim M. Taqi, ${ }^{1}$ Badriya H. Al-Kendi, ${ }^{1}$ Hani Al-Qadhi ${ }^{2}$

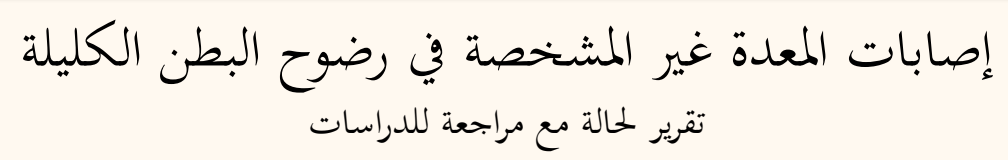

$$
\text { أحمد أشرف نعيم، كاظم مصطفى تقي، بدرية حمود الكندية، هاني القاضي }
$$

ABSTRACT: Hollow viscus injuries of the digestive tract are an uncommon occurrence in blunt abdominal trauma. We report a 39-year-old male who was hit by a vehicle as a pedestrian and admitted to the Sultan Qaboos University Hospital, Muscat, Oman, in 2015. He underwent an exploratory laparotomy which revealed injuries to the distal stomach, liver and descending colon. Postoperatively, the patient was febrile, tachycardic and hypotensive. Abdominal examination revealed distention and tenderness. The next day, a repeat laparotomy identified a gastric injury which had not been diagnosed during the initial laparotomy. Although the defect was repaired, the patient subsequently died as a result of multiorgan failure. Missed gastric injuries are rare and are associated with a grave prognosis, particularly for trauma patients. Delays in diagnosis, in addition to associated injuries, contribute to a high mortality rate.

Keywords: Abdominal Injuries; Blunt Injuries; Trauma; Diagnostic Errors; Laparotomy; Case Report; Oman.

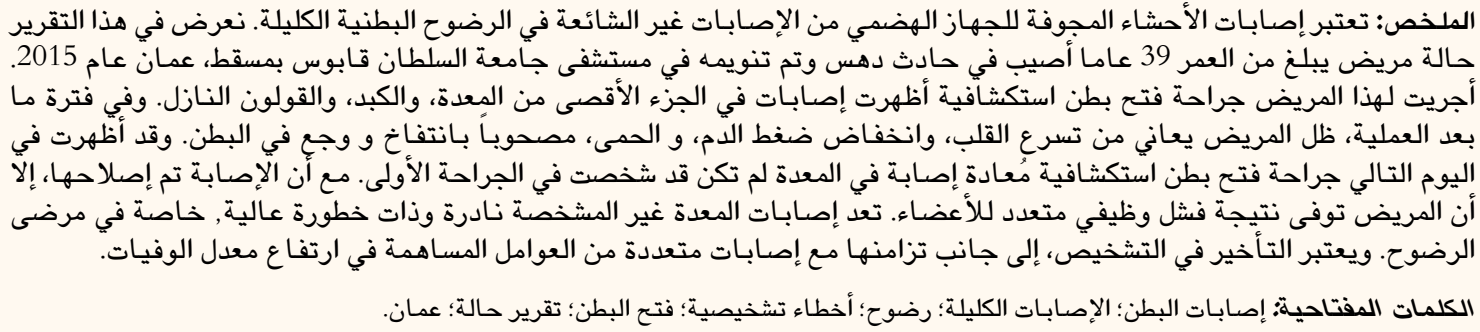

\section{$\mathrm{T}$} He stomach is less commonly affected by hollow viscus injuries (HVIs) following blunt trauma, making up $4.3 \%$ of total cases. ${ }^{1}$ It is estimated that trauma surgery departments only encounter approximately 14 cases of HVIs annually, with a prevalence of $0.3-1.2 \%{ }^{1-3}$ Despite this, HVIs account for $17.8 \%$ of all missed injuries in blunt trauma in comparison to solid organs such as the spleen (8.9\%) and liver (3.3\%); as such, a HVI is the most frequently missed organ injury. ${ }^{4}$ Following blunt abdominal trauma (BAT), gastric injuries have a higher mortality rate compared to other HVIs, reaching up to $28.2 \%$ in cases with stomach injuries compared to $15.2 \%$ for small bowel injuries and 19.4\% for injuries to the colon and rectum. ${ }^{1}$

\section{Case Report}

A 39-year-old male pedestrian was hit by a vehicle and brought by the emergency medical services to the Emergency Medicine Department of the Sultan
Qaboos University Hospital, Muscat, Oman, in 2015. The patient was managed according to Advanced Trauma Life Support ${ }^{\circledR}$ protocols (American College of Surgeons, Chicago, Illinois, USA). The primary survey was unremarkable and the secondary survey was normal apart from an externally rotated right foot. After initial resuscitation with fluids, computed tomography $(\mathrm{CT})$ imaging of the patient revealed a moderate amount of free intraperitoneal air [Figure 1], suggestive of a bowel perforation. In addition, a lower limb X-ray revealed a comminuted open fracture of the right tibia.

The patient underwent an exploratory laparotomy followed by intramedullary nailing of the tibial fracture and debridement of the wound. The laparotomy indicated free fluid and blood in the peritoneal cavity and a $2 \mathrm{~cm}$ serosal laceration on the posterior aspect of the distal stomach with a contained haematoma. Primary wound closure was performed using 3-0 Vicryl $^{\circledR}$ sutures (Ethicon Inc., Johnson \& Johnson, Somerville, New Jersey, USA). A non-bleeding liver 


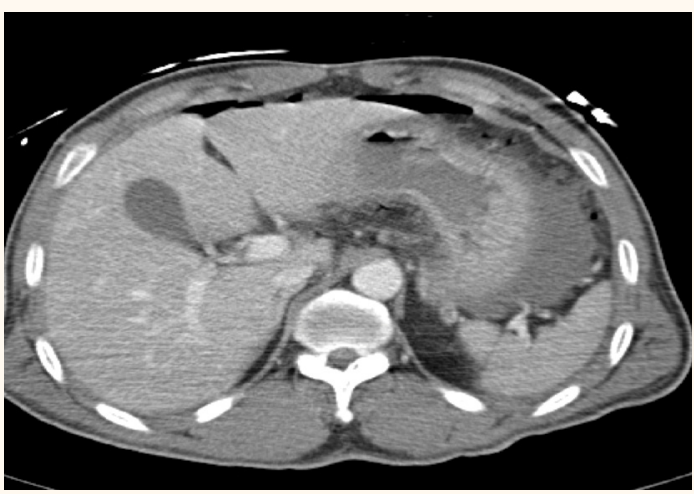

Figure 1: Computed tomography scan with contrast of a 39-year-old male with blunt abdominal trauma. There is evidence of a moderate amount of free intraperitoneal air as well as fluid in the left upper quadrant between the stomach and the spleen and more surrounding the stomach. Fluid can also be seen around the duodenum.

injury and a serosal tear of the descending colon were also observed. No bowel perforation was identified upon running the bowel three times from the stomach to the rectum, both anteriorly and posteriorly. The abdomen was subsequently closed and the patient was extubated and transferred to the Intensive Care Unit (ICU).

The next day, the patient was febrile, tachycardic and hypotensive. Abdominal examination revealed distention and tenderness. A repeat CT scan of the chest and abdomen showed increased pneumoperitoneum [Figure 2], necessitating a repeat exploratory laparotomy carried out on the same day. This revealed that the abdominal cavity was soiled with bowel content and inflammatory fluid. There was a $3 \times 3 \mathrm{~cm}$ perforation with necrotic edges at the distal greater curvature of the stomach. The edges of the perforation were resected and the defect closed with a single interrupted 3-0 Vicryl ${ }^{\circledR}$ suture (Ethicon Inc.).

The patient was transferred back to the ICU after the repeat laparotomy. Four days after the initial exploratory laparotomy, he developed multiple episodes of asystole and was resuscitated. Post-resuscitation, there was evidence of multiorgan failure manifesting as a severe hypoxic brain injury, acute respiratory distress syndrome, liver failure and an acute kidney injury requiring continuous venovenous haemodialysis and vasopressors. The patient subsequently died on the $10^{\text {th }}$ postoperative day following the initial laparotomy.

\section{Discussion}

Blunt trauma can result in injuries to the gastrointestinal tract via different mechanisms. An external force against the thorax and abdomen, such as that of a seatbelt or steering wheel, can crush a distended part of the gastrointestinal tract against the vertebral

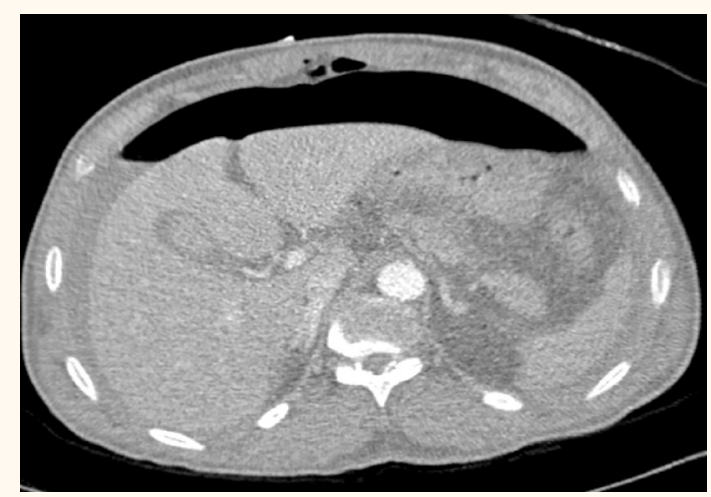

Figure 2: Repeat computed tomography scan with contrast following an explorative laparotomy and stomach laceration repair of a 39-year-old male with blunt abdominal trauma. There is evidence of increased pneumoperitoneum, necessitating a repeat laparotomy.

column, resulting in rupture of the bowel and its mesentery. ${ }^{5}$ Moreover, deceleration forces encountered while in a sharply braking vehicle can disrupt bowel integrity at the junctions between the freely mobile and fixed segments of the gastrointestinal tract, giving rise to varying degree of tears and devascularising injuries. ${ }^{3}$

Missed injuries and delayed diagnoses are attributed to many causes, most of which are multifactorial. ${ }^{1}$ Common patient-related factors include an altered level of consciousness, delayed presentation, haemodynamic abnormalities and the presence of other distracting injuries. ${ }^{2}$ The most frequent physicianrelated factors include deficiencies in clinical assessment or judgment as well as the inaccurate interpretation of results and imaging studies. ${ }^{6}$ In addition, an initially low index of suspicion for HVIs and incomplete surgical exploration are significant contributing factors. ${ }^{6}$ In the current case, the primary and secondary surveys focused more on the distracting lower limb injury and the presence of CT-proven pneumoperitoneum. The initial exploratory laparotomy revealed nothing to explain the radiological findings. These factors could have contributed to a delayed diagnosis. Tertiary surveys may detect significant injuries missed during primary and secondary surveys. ${ }^{7}$

Gastric injuries are usually associated with a high injury severity score. ${ }^{1}$ Moreover, although rare in BAT, these injuries carry the highest mortality rate among HVIs. ${ }^{1,6-8}$ The most commonly affected part of the stomach is the anterior stomach wall (40\% of total gastric injuries), followed by the greater (23\%) or lesser (15\%) curvature of the stomach and the posterior stomach wall (15\%). ${ }^{7}$ Most gastric injuries are superficial haematomas and serosal tears, whereas full thickness perforations occur less commonly (0.3\%). ${ }^{1}$ A proposed classification for traumatic gastric 
Table 1: Classification of traumatic gastric injuries ${ }^{9}$

\begin{tabular}{|c|c|c|}
\hline Grade & Injury type & Description of injury \\
\hline \multirow[t]{2}{*}{ I } & \multirow[t]{2}{*}{$\begin{array}{l}\text { Haematoma } \\
\text { or contusion }\end{array}$} & $\begin{array}{l}\text {-Haematoma or contusion without } \\
\text { devascularisation }\end{array}$ \\
\hline & & $\begin{array}{l}\text { - Partial thickness laceration of the } \\
\text { stomach wall }\end{array}$ \\
\hline \multirow[t]{3}{*}{ II } & \multirow[t]{3}{*}{ Laceration } & $\begin{array}{l}\text { - Laceration of } \leq 2 \mathrm{~cm} \text { in the } \\
\text { gastroesophageal junction or pylorus }\end{array}$ \\
\hline & & $\begin{array}{l}\text { - Laceration of } \leq 5 \mathrm{~cm} \text { in the proximal } \\
\text { third of the stomach }\end{array}$ \\
\hline & & $\begin{array}{l}\text { - Laceration of } \leq 10 \mathrm{~cm} \text { in the distal } \\
\text { two-thirds of the stomach }\end{array}$ \\
\hline \multirow[t]{3}{*}{ III } & \multirow[t]{3}{*}{ Laceration } & $\begin{array}{l}\text { - Laceration of }>2 \mathrm{~cm} \text { in the } \\
\text { gastroesophageal junction or pylorus }\end{array}$ \\
\hline & & $\begin{array}{l}\text { - Laceration of }>5 \mathrm{~cm} \text { in the proximal } \\
\text { third of the stomach }\end{array}$ \\
\hline & & $\begin{array}{l}\text { - Laceration of }>10 \mathrm{~cm} \text { in the distal } \\
\text { two-thirds of the stomach }\end{array}$ \\
\hline IV & $\begin{array}{l}\text { Vascular } \\
\text { injury }\end{array}$ & $\begin{array}{l}\text { Tissue loss or devascularisation of } \\
\text { two-thirds of the stomach or less }\end{array}$ \\
\hline V & $\begin{array}{l}\text { Vascular } \\
\text { injury }\end{array}$ & $\begin{array}{l}\text { Tissue loss or devascularisation of } \\
\text { more than two-thirds of the stomach }\end{array}$ \\
\hline
\end{tabular}

injuries is detailed in Table $1 .^{9}$

Patients with gastric injuries secondary to BAT usually have a nonspecific presentation, possibly due to shock; as such, abdominal tenderness or rigidity and fevers are less likely to be clinically evident. ${ }^{1}$ Diagnostic tools range from plain films to ultrasonography and CT; in addition, a diagnosis can be made during a diagnostic or exploratory laparotomy. ${ }^{8}$ The management of such injuries involves initial fluid resuscitation followed by laparoscopic or open debridement of the wound with primary closure or a partial gastrectomy. ${ }^{10}$

\section{Conclusion}

Traumatic HVIs, when missed, are a major cause of morbidity and mortality. In a trauma setting, injuries usually involve multiple systems, many of which can complicate clinical assessment and diagnosis. Moreover, the presentation of gastric injuries is generally nonspecific. Trauma teams should therefore have a high index of suspicion for HVIs when treating severely injured patients.
1. Watts DD, Fakhry SM; EAST Multi-Institutional Hollow Viscus Injury Research Group. Incidence of hollow viscus injury in blunt trauma: An analysis from 275,557 trauma admissions from the East Multi-Institutional Trial. J Trauma 2003; 54:289-94. doi: 10.1097/01.TA.0000046261.06976.6A

2. Sung CK, Kim KH. Missed injuries in abdominal trauma. J Trauma 1996; 41:276-82. doi: 10.1097/00005373-19960800000013.

3. Tejerina Alvarez EE, Holanda MS, López-Espadas F, Dominguez MJ, Ots E, Díaz-Regañón J. Gastric rupture from blunt abdominal trauma. Injury 2004; 35:228-31. doi: 10.1016/ S0020-1383(03)00212-2.

4. Lawson CM, Daley BJ, Ormsby CB, Enderson B. Missed injuries in the era of the trauma scan. J Trauma 2011; 70:452-6. doi: 10.1097/TA.0b013e3182028d71.

5. Shinkawa H, Yasuhara H, Naka S, Morikane K, Furuya Y, Niwa H, et al. Characteristic features of abdominal organ injuries associated with gastric rupture in blunt abdominal trauma. Am J Surg 2004; 187:394-7. doi: 10.1016/j.amjsurg.2003.12.018.

6. Allen GS, Moore FA, Cox CS Jr, Wilson JT, Cohn JM, Duke JH. Hollow visceral injury and blunt trauma. J Trauma 1998; 45:69-75. doi: 10.1097/00005373-199807000-00014.

7. Rodríguez-Hermosa JI, Roig J, Sirvent JM, Codina-Cazador A, Gironès J, Puig J, et al. Gastric perforations from abdominal trauma. Dig Surg 2008; 25:109-16. doi: 10.1159/000121906.

8. Brooks A, Holroyd B, Riley B. Missed injury in major trauma patients. Injury 2004; 35:407-10. doi: 10.1016/S0020-1383(03) 00219-5.

9. Moore EE, Jurkovich GJ, Knudson MM, Cogbill TH, Malangoni MA, Champion HR, et al. Organ injury scaling: VI Extrahepatic biliary, esophagus, stomach, vulva, vagina, uterus (nonpregnant), uterus (pregnant), fallopian tube, and ovary. J Trauma 1995; 39:1069-70. doi: 10.1097/00005373-19951200000009.

10. Pikoulis E, Delis S, Tsatsoulis P, Leppäniemi A, Derlopas K, Koukoulides G, et al. Blunt injuries of the stomach. Eur J Surg 1999; 165:937-9. doi: 10.1080/110241599750008035.

\section{References}

